\title{
Factors Influencing Customer Satisfaction and Its Contribution on Customer Loyalty: Case of Restaurant Industry in Turkish Republic of North Cyprus
}

\author{
Ercem RUHLUEL iD a Pelin BAYRAM iD b \\ a Eastern Mediterranean University, Faculty of Business and Economics, Turkish Republic of Northern Cyprus, Turkey. \\ ruhluel_1907@hotmail.com \\ b European University of Lefke, Faculty of Economics \& Administrative Sciences, Department of Business Administration, Turkish \\ Republic of Northern Cyprus, Turkey. pbayram@eul.edu.tr
}

\begin{tabular}{|c|c|}
\hline ARTICLE INFO & ABSTRACT \\
\hline $\begin{array}{l}\text { Keywords: } \\
\text { Customer Satisfaction } \\
\text { Customer Loyalty } \\
\text { Service Quality } \\
\text { Mobile Application } \\
\text { Restaurant Industry }\end{array}$ & $\begin{array}{l}\text { Purpose - The purpose of our study is to analyze the customer satisfaction and loyalty in restaurant } \\
\text { industry in Turkish Republic of Northern Cyprus. Considering the restaurant industry, the literature reveals } \\
\text { that food quality, service quality, price, location and restaurant atmosphere are the key determinants of } \\
\text { customer satisfaction. Although positive relationships were reported in many studies between the } \\
\text { traditional determinants and customer satisfaction, it is important to investigate these factors in TRNC since } \\
\text { the dynamics and culture of each country can be different. }\end{array}$ \\
\hline $\begin{array}{l}\text { Received } 11 \text { May } 2021 \\
\text { Revised } 12 \text { September }\end{array}$ & $\begin{array}{l}\text { Design/methodology/approach - In this study, 7-point Likert scale survey instrument was constructed and } \\
\text { online questionnaire distributed to survey } 356 \text { customers through convenience sampling method. } \\
\text { Classification and Regression Tree (CART) Analysis was used to test the hypotheses. }\end{array}$ \\
\hline $\begin{array}{l}2021 \\
\text { Accepted } 15 \text { September } \\
2021\end{array}$ & $\begin{array}{l}\text { Findings - Our findings indicate that service quality and food quality make significant contribution on } \\
\text { customer satisfaction and there is a positive relationship between customer satisfaction and customer } \\
\text { loyalty. In addition, food quality is the most important factor influencing the customer satisfaction in } \\
\text { restaurant industry. }\end{array}$ \\
\hline $\begin{array}{l}\text { Article Classification: } \\
\text { Research Article }\end{array}$ & $\begin{array}{l}\text { Discussion - In addition to traditional determinants, usage of mobile application and presentation shows } \\
\text { in restaurants were incorporated into the proposed research model to examine the relationship with } \\
\text { customer satisfaction. Mobile application and presentation shows were rarely investigated in restaurant } \\
\text { industry and since there is a hyper-competition in restaurant industry, it is important to find new ways that } \\
\text { can promote to customer satisfaction. Furthermore, the relationships between customer satisfaction and } \\
\text { loyalty is investigated. }\end{array}$ \\
\hline
\end{tabular}

\section{INTRODUCTION}

The Turkish Republic of Northern Cyprus (TRNC) is an island which is located in the northeastern section of the Cyprus Island. The Cyprus Island exposed to war for long years between Turkish and Greek societies and the island has divided into two parts by the invasion of Turkey in 1974. Cyprus is the third largest island of Mediterranean Sea. Restaurant industry is one of the most alive industries in North Cyprus due to sunny weather condition of the island. Therefore, the demand of food service is always high and it attracts investors to invest into this industry. Increased number of restaurants provides sufficient job alternatives and this is beneficial for decreasing the unemployment rate of the country. Thus the restaurant industry is having significant contribution to overall economy of TRNC. In addition, TRNC welcomes high number of tourists continuously due to island's suitable weather conditions and the industry provides different variety of international cuisines to satisfy the needs of their local and international customers. Apart from the high number of tourists, another customer source of the industry is university students. In 2018-2019 academic year, there were 12,508 domestic students, 54,875 Turkish citizen students and 35,318 foreign students and in total there were 90,193 students in TRNC (Ministry of National Education and Culture, 2019). In line with the above, we can conclude that the restaurant industry is a highly competitive industry.

The number of restaurants increasing continually and the competition allows customers to make a selection based on their level of satisfaction. Therefore to avoid customer churn and to retain the customer, industry's 


\section{E. Ruhluel - P. Bayram 13/3 (2021) 2305-2319}

focus is purely on customer satisfaction as the satisfaction is one of the most significant factor to survive in a highly competitive environment. Food quality, service quality and price are widely covered in the literature as the determinants of customer satisfaction in restaurant industry (Haghighi \& Hoseinpour, 2012). However, the results can vary in different countries since every country have its own culture and values. Zhang \& Law (2013) investigated the customer satisfaction in restaurant industry and their results indicate that determinants of customer satisfaction are changing based on the different location in China. Besides, North Cyprus restaurant industry is challenging with the intense competition and the restaurants are aware of the importance of satisfaction. Thus more or less they try to provide similar values for their customers. In such situations, traditional determinants such as food quality and service quality is insufficient in explaining customer satisfaction. Therefore, our study has incorporated mobile application and presentation show into the research model to test the effect on customer satisfaction based on the suggestion made by Balasubramanian \& Balraj (2015). In addition, our research also measures the effect of customer satisfaction on customer loyalty.

The purpose of our research is to investigate the factors effecting customer satisfaction in restaurant industry through the determinants widely covered in literature such as food quality, service quality, price, atmosphere and location (Han \& Ryu, 2009; Markovic \& Dorcic, 2011; MacLaurin \& MacLaurin, 2000; Hanaysha, 2016) as well as contribution of mobile application and presentation shows. The relationship between customer satisfaction and loyalty is also examined.

\section{LITERATURE REVIEW AND HYPOTHESES DEVELOPMENT}

\subsection{Customer Satisfaction}

The importance of customer satisfaction has explained by many scholars in previous studies. According to Kotler (2000, p.36) customer satisfaction is a consumer's emotion of enjoyment or displeasure about the product's perceived performance in relation to consumer's expectation. Concept of satisfaction have been associated with some emotions such as acceptance, happiness, relief, excitement and delight (Singh, 2006). Hokanson (1995), stated that the factors of customer satisfaction include sincere, polite, well informed and helpful employees, price fairness, billing on time, clearness of billing, quality of service and early service. Customer's feeling of satisfaction through the consumption of goods and services is companies' primary source of gaining competitive advantage and reaching success (Hennig \& Klee, 1997). Customer satisfaction considered as key point on long term behavior and on purchase intentions. As long as customers are satisfied, they continue to purchase. LaBarbera \& Mazursky (1983) states that customer satisfaction has positive impacts on repurchase intention and dissatisfaction is the first reason of losing a customer. The importance of repurchase behavior is also valid for restaurant industry. According to Liu \& Jang (2009), providing continuous customer satisfaction is vital factor for the repeat patronage in restaurant industry. Profitability, return on investment and market share are perhaps the most important goals and missions of a company and Hackl \& Westlund (2000) indicated that, it's highly important to create customer satisfaction as satisfied customers lead to increase in market share, return on investment and profitability.

The restaurant industry is highly competitive industry that requires high level of customer satisfaction. Gagic et al. (2013) suggested that restaurant sector is developing across the world continually and people have more available options when they want to eat outside. Therefore, Haghighi \& Hoseinpour (2012) argued that to be selected, restaurant managers should examine what is value for customers when choosing a restaurant among alternatives. The significance of understanding the value creation process in restaurant industry was highlighted by different scholars in the literature. Hwang \& Zhao (2010) suggested that the sales rate of restaurants depend on the level of customer satisfaction. So it is significant requirement to find and understand what is valuable for customers. Restaurants have risk to fail if they cannot meet the needs and wants of today's customers. Parsa et al. (2005) made an argument on continuously changing trends in food industry by using an example of healthy food menus which recently became very popular. Thus, following the new trends and understanding the changes in needs and wants of customers are the key elements of customer satisfaction.

\subsection{Determinants of Customer Satisfaction}

A considerable amount of literature has been published on factors influencing customer satisfaction and loyalty in restaurant industry. Food quality, service quality, price fairness and physical environment of the 
restaurant are defined as key factors effecting customer satisfaction. Studies have used different methodologies but majority of them have used quantitative approaches in data analysis procedure.

\subsubsection{Food Quality}

During the past 20 years, the microbiological, chemical and nutritional quality become insufficient for customers in rating the food quality (Cardello \& Armand V, 1995). Galvez \& Resurrecion (1992) stated that food quality improves the perceived characteristic of the food by the purchaser. The term perceived characteristic emphasize sensorial side of food such as taste, appearance and size as well as its cost. Due to hyper competition in restaurant industry most of the menus offer similar or same foods for their customers. Since they have similar products, a restaurant can create differentiation or gain a competitive advantage based on the taste of foods. The food quality perhaps is the most important factor in terms of creating customer satisfaction in restaurant industry, but the evaluation of high or low quality for food varies from person to person, because each person has own taste, liking or pleasure and this makes food quality criteria complex. Haghighi, Dorosti, Rahnama and Hoseinpour (2012) examined the factors that have effect on customer satisfaction. Their findings indicate that food quality, service quality, price, restaurant location and atmosphere have positive effect on customer satisfaction and trust. Likewise, Sabir et al. (2014) investigated the relationship between service quality, price and environment of restaurants and customer satisfaction. The hypotheses of positive relationship between the determinants and customer satisfaction have been confirmed. In addition, findings were showing the positive effect of customer satisfaction on customer loyalty. In parallel, Butt \& Murtaza (2011) explored the relationship between customer satisfaction and its determinants and their findings showed that food and service quality creates a strong bond between customers and restaurants which leads to increase in profitability and satisfaction. Hence we propose the following hypothesis:

H1: Food quality positively influences the customer satisfaction.

\subsubsection{Service Quality}

Studies on service quality has been widely covered in literature. Parasuraman et al. (1988) created SERVQUAL scale to measure inconsistency degree between the customer's expectation and perceived performance of the service. This scale uses five dimension as main factors of service quality which are tangibles, reliability, responsiveness, assurance, and empathy. After the formation of SERVQUAL, scale was used in many researches for measuring the service quality in different business industries (Fu \& Parks, 2001; Gounaris, 2005; Lee \& Ulgado, 1997; Furrer et al., 2000). Furthermore, Stevens et al. (1995), used these dimensions and stated that reliability is the most important dimension. The study of Zopiatis \& Pribic (2007), reported similar results where the reliability is the most important but the second one is responsiveness and then tangibles, assurance and empathy. Qin \& Prybutok (2009) suggest that qualified service performance creates pleased and loyal customers and the loyalty is crucial in terms of repurchase in fast food restaurants. Conversely low service performance creates unsatisfied customers which causes a customer churn to alternative restaurants and these unsatisfied customers can influence others through spreading negative word of mouth.

According to Gray \& Boshoff (2004) if customers feel satisfied by the service quality of restaurant, they have tendency to become loyal to that particular entity. The service delivery quality of restaurant includes tiny details such as presentation of food, type, shape and hygiene of plates, putting fork and knife right side, taking customers' order in time, trustworthiness, assurance and cleanliness of tables. Similar to food quality evaluation, service quality evaluation is personal situation and cannot be identical for every customer. This shows us heterogeneity feature of service dimension. Each customer has their own criteria when evaluating service quality. Furthermore, the service providers are waiters, thus service quality in a restaurant mainly depends on human effort. In parallel to above discussion this study adopts the concept of SERVEQUAL and posits the following hypothesis.

H2: Service quality positively influence customer satisfaction

\subsubsection{Price}

Price fairness is an evaluation made by customers through comparing the quality and performance of the product based on its price. Xia et al. (2004) stated that price fairness means evaluating the seller's pricing attitude, if it is fair and logical. Positive evaluation of customer is vital for firms' success, and has highly 


\section{E. Ruhluel - P. Bayram 13/3 (2021) 2305-2319}

positive effect on purchase intentions. Positive effect on purchase intention emphasizes repurchase or more frequent purchases for same product. Mankaa (2012) stated that customers look prices and quality of the food and they evaluate if the quality of food deserves its price or not. If they think the given price of the food doesn't match the quality they feel dissatisfied. Chandrashekaran \& Grewal (2003) indicates that customers who have price fairness stored in their minds, means consumer had experiences and perceptions which are formed in their previous restaurant visits. They use these stored memories when they evaluating price fairness of any restaurant. Hence, price is considered as a factor influencing customer satisfaction and therefore, we hypothesize;

H3: Price positively influence customer satisfaction

\subsubsection{Restaurant Atmosphere}

Quality of the restaurant atmosphere depends on the physical environment inside the facility. It includes lightning, hygiene and attractive air quality, and level of temperature. They all can be controlled and can be adjusted by companies. Thus, the term physical environment's contents and features are different from natural environment which is generally uncontrollable by humans. Physical environment also include human-made environment such as walls, plants and furniture. According to the environmental psychology research of Mehrabian \& Russel (1974) there is a powerful relationship between physical surroundings and human behavior. The theory in their study argues that in general, humans give two types of responses to physical environment. These are approach and avoidance. The approach behavior indicates positive human behaviors such as willingness to stay and the avoidance behavior indicates negative responses such as unwillingness to stay. It's clear that the feel or response of willingness to stay occurs from the feeling of satisfaction Thus, this shows us, if the physical environment designed carefully it can positively affects the customer satisfaction.

Wakefield \& Blodgett (1994) stated that arranging the layout in the facility correctly provide feel of comfort to customers and make contribution on meeting the functional need of customers. The physical environment of a business is an important determinant on business image which in turns affect behavior of customers and this situation is suitable to restaurant industry (Hul et al., 1997; Milliman, 1986). Moreover, the research of Chang (2000), indicates that physical environment and customer satisfaction are directly related. The direct relationship means customer satisfaction increase when level or quality of physical environment is high. According to Ryu \& Han (2010) it's true that food and service quality is important point for customer satisfaction but creating delightful physical environment for consumers which include lightning, decor, layout and employee appearance have big effect on overall satisfaction and behavioral intentions. Thus, we hypothesize;

H4: Restaurant atmosphere positively influence customer satisfaction

\subsubsection{Location}

Selecting appropriate and right location is vital for every entity in reaching success to Parsa et al. (2005). The term location refers to place, city and street where you establish your facility. Choosing a location that is easy for transportation is important factor that must be taken into account. Li et al. (2015) recommended that successful marketing performance highly depends on location selection. Wang, Tran \& Nguyen (2014) found that customers become more loyal to the brand if the right location is selected by companies. Their arguments tell us their loyalty increase with right location strategy of firms creates high satisfaction and in return provide increase in customer loyalty. Another arguments was used by Azim \& Bagram (2014) their research suggested that location is important criteria in selecting restaurant to dine out. Furthermore, Hanaysha (2016) indicated that restaurant location has significant positive effect on brand loyalty and on brand preferences of customers. In addition, Melia (2010) states a company should follow and examine its competitors about what they do, where they select and how they select their locations to create appropriate and effective location selection strategy for gaining competitive advantages. When a company set up its business on a better location than competitors, this strategically provide them long-term surviving possibilities. Therefore, propose the following hypothesis.

H5: Location of a restaurant positively influence customer satisfaction. 


\subsubsection{Presentation show}

In recent years some restaurants start using presentation shows in presenting the food to their customers. Especially this shows used for meat such as steaks and most of the restaurants have steak in their menus. However presentation shows can be applied to other products in a restaurant as well. It can also be performed by using interesting plates such as shoe-shaped plates. Extensive literature review showed us that presentation shows have not been examined yet in relation to customer satisfaction. Presentation shows can contribute to customer satisfaction and may be new leading factor on customer satisfaction in coming years. One of the recent presentation show has been done by Nusr-et which is a steak house and their presentation shows become popular virally on social media platforms. Another example is presenting or pouring the sauces to the meals in front of the customers. Restaurants also starts to use this type of presentation shows on deserts.

The key point for the presentation shows to create opportunity for customers to take videos and photos. They record the shows presented by waiters and shares on their social media accounts to collect "likes" and "comments" as well as increasing numbers of followers. Thus these type of shows creates visuality, excitement and entertainment for customers and this arouses curiosity and desire to experience the same event. Secondly, they have chance of recording these shows both for storing as memory and for sharing in their social media accounts. Therefore, our research added presentation show as one of the component of service quality to measure the effect on customer satisfaction and developed the following hypothesis.

H6: Presentation shows positively influence customer satisfaction

\subsubsection{Mobile application}

Due to rapid increase in technology all the dynamics in the world are changing. One of the most used technological device is smartphones since it provides very practical and simultaneous transaction opportunities. O'dea (2020) suggest that number of smartphone users have reached to 3, 5 billion in 2020. Because of high usage rate of smartphones, applications become so popular and important tool for almost all businesses. An application programs is a designed program to perform specific functions for the users. Companies can show their products, services, prices, locations and other features to customers by a mobile applications. Only few studies were conduct to measure effect of mobile apps on customer satisfaction in restaurant industry.

On the other side, using the benefit of mobile apps widely covered in tourism and hospitality literature. According to Jacobs (2011) by bookings from mobile websites and applications, the Intercontinental hotels group gain at least $\$ 130$ million. Heller (2011) stated that in 2011 , the number of booking by using phone application is 100,000 and this provide an increase in revenue by $200 \%$ to Hilton Hotels.

Basically the term customer satisfaction in restaurant industry is associated with experiencing the presented foods, services, prices and physical environment. However, the mobile application creates new dimensions and opportunities for customer satisfaction. A specifically designed mobile application of a restaurant can show its products, services, location, prices, and photos of facility prior of visit. This current research considers the suggestion done by Balasubramanian \& Balraj (2015) and incorporated mobile phone applications in to proposed research model and propose the following hypothesis:

H7: Mobile phone application positively influence customer satisfaction

\subsection{Relationship between Satisfaction and Loyalty}

The term "Customer loyalty" is one of the most important factor for companies to survive in the highly competitive markets. The firm's primary goal or strategy is to increase their loyal customer base. Oliver (1997), stated that customer loyalty is a "deeply held commitment to re-buy or re-patronize a preferred product or service consistently in the future, despite situational influences and marketing efforts having the potential to cause switching behavior". In short, customer loyalty is a strong commitment to a brand (Khan, 2012). Yang \& Peterson (2004) stated that as a result of loyalty, customers more of the product and spread positive word of mouth which in return increase the income of the company. In addition, Bowen \& Chen (2001) indicated that customer loyalty provides low market costs and high profit margins. Furthermore, Bansal \& Gupta (2001) argued that creating customer loyalty is not an option for businesses as it is the only factor for the formation of long term competitive advantage. 
In today's competitive business environment, customer retention gained more importance because attracting new customer cost more than retaining the existing customer. Customer satisfaction has founded as the most influential factor in increasing customer loyalty. Thus the relationship between customer satisfaction and customer loyalty must be examined in detail and must be taken in to account. However, even customer satisfaction may not be the only factor that improves customer loyalty, improving the level of customer satisfaction is the main effect to increase level of loyalty (Han \& Ryu, 2009). Shahin \& Javadi (2011) stated if firms want to increase customer loyalty they first should measure customer satisfaction. The relationship between customer satisfaction and loyalty has been widely covered in marketing literature. Most studies have confirmed the positive relationship between satisfaction and loyalty (Hoyer \& Pieters, 2001; Eshghi \& Topi, 2007; Anderson \& Sullivan, 1993; Bearden \& Teel, 1983; LaBarbera \& Mazursky, 1983; Oliver, 1980). Therefore, we hypothesize;

H8: Customer satisfaction has positive effect on customer loyalty

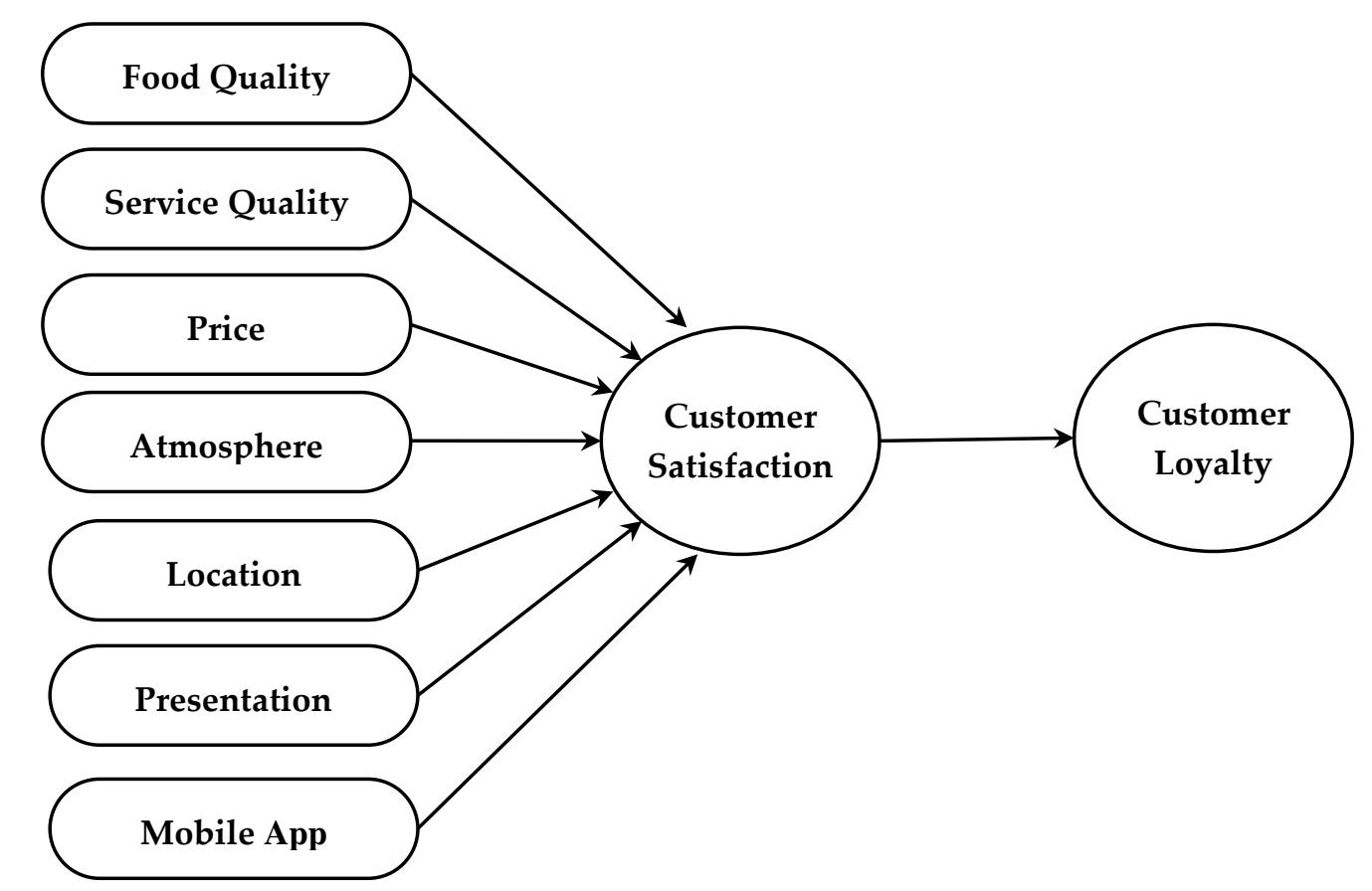

Figure 1. The conceptual model

\section{METHODOLOGY}

\subsection{Sample and procedures for data collection}

Our study employed a convenience sampling method for the data collecting process and online questionnaire were sent to residents in North Cyprus through social networking websites as the most appropriate way to reach TRNC residents. To reduce the error possibility in results all questions in questionnaires asked respondents their last restaurant experience in TRNC. By this way, only those who have experienced a restaurant in TRNC before will answer the questions. The questionnaire translated into the Turkish language for the purpose of the content clarity and validity of the questionnaire. Respondents rated items on sevenpoint Likert scales where $1=$ "Strongly Disagree" and $7=$ "Strongly Agree" and we obtained 356 complete questionnaires. Since the aim is representing insights of a whole country, the population of that research is very high. The population to be represented in that research study was 286,257 , which is entire TRNC population. When it's very hard or impossible to reach entire population to collect data, using convenience sampling is suitable, helpful and generally only possible option. Quantitative approach was used which emphasizes quantification in the collection and analyses of the data and based on objective facts and statistics. 


\subsection{Measurements}

Customer satisfaction was measured by adopting three items from Oliver (1980). The customer loyalty was tested by adopting three items from Liao \& Chuang (2004). The items for food quality, service quality, price, restaurant atmosphere and location adapted from Andaleeb \& Conway (2006). The items for mobile application inspired from further research suggestion of Balasubramanian \& Balraj (2015) who suggested further research is needed on mobile application and the items are developed by the authors of this article.

\section{DATA ANALYSIS}

\begin{tabular}{lll}
\hline & Table 1.Reliability measures of sub-scales & \\
\hline Scale & Number of Items & $\alpha$ \\
\hline Customer Satisfaction & 3 & 0.89 \\
Food Quality & 2 & 0.81 \\
Service Quality & 7 & 0.92 \\
Mobile Application & 3 & 0.85 \\
Restaurant Atmosphere & 3 & 0.83 \\
Price & 2 & 0.72 \\
Customer Loyalty & 3 & 0.82 \\
\hline
\end{tabular}

Cronbach alpha reliability coefficient, $\alpha=0.94$, of the whole scale and its sub-scales are all in the acceptable range (see Table 1). Since there was only one item for location, reliability measure for this item was not performed.

Table 2. Spearman Rho correlation coeffients among the variables.

\begin{tabular}{lccccccccc}
\hline & 1 & 2 & 3 & 4 & 5 & 6 & 7 & 8 & 9 \\
\hline 1. Customer Satisfacion & 1.000 & & & & & & & & \\
2. Loyalty & $.526^{*}$ & 1.000 & & & & & & \\
3. Service Quality & $.676^{*}$ & $.588^{*}$ & 1.000 & & & & & \\
4. Food Quality & $.604^{*}$ & $.564^{*}$ & $.656^{*}$ & 1.000 & & & & \\
5. Mobile App. & $.339^{*}$ & $.402^{*}$ & $.416^{*}$ & $.417^{*}$ & 1.000 & & & & \\
6. Restaurant Atmos. & $.527^{*}$ & $.515^{*}$ & $.630^{*}$ & $.625^{*}$ & $.411^{*}$ & 1.000 & & \\
7. Price & -.042 & -.009 & .019 & -.024 & $.121^{*}$ & .092 & 1.000 & \\
8. Location & $.349^{*}$ & $.349^{*}$ & $.401^{*}$ & $.386^{*}$ & $.287^{*}$ & $.430^{*}$ & .068 & 1.000 & \\
9. Presentation Shows & $.330^{*}$ & $.418^{*}$ & $.472^{*}$ & $.389^{*}$ & $.440^{*}$ & $.574^{*}$ & .084 & $.401^{*}$ & 1.000 \\
\hline
\end{tabular}

"Significant at $p<.001$

In order to determine bivariate correlation coefficients among the variables (rank order) Spearman's Rho correlational analysis was used. As seen in Table 2, the highest significant correlation (high correlation) is between customer satisfaction and service quality $(r=0.676)$ and the customer satisfaction has a significantly weak correlation $(r=0.330)$ with presentation shows. Lowest significant correlation is between price and mobile applications. Price is only significantly correlated with mobile applications. Loyalty and customer satisfaction scores are moderately correlated. In interpreting the correlation coefficients Dancey \& Reidy (2007) measures were used. 
E. Ruhluel - P. Bayram 13/3 (2021) 2305-2319

Table 3. Two-step cluster analysis results regarding customer satisfaction scores.

\begin{tabular}{llllllll}
\hline Cluster & Sub-Group & $\boldsymbol{F}$ & $\mathbf{\%}$ & Min. & Max. & $\overline{\boldsymbol{X}}$ & $\boldsymbol{s d}$ \\
\hline & Low Score Group & 49 & 13.80 & 3 & 10 & 7.12 & 2.27 \\
& Medium Score Group & 169 & 47.60 & 11 & 16 & 13.98 & 1.57 \\
\multirow{2}{*}{ Customer Satisfaction } & High Score Group & 137 & 38.60 & 17 & 21 & 19.04 & 1.43 \\
& Total & 355 & 100 & 3 & 21 & 14.99 & 4.24 \\
\hline
\end{tabular}

As we obtained the respondents' customer satisfaction scores from distinct layers of population, the data set separated in to homogeneous subgroups by using two-step cluster analysis (Chiu, Fang, Chen \& Wang, 2001). By using two-step cluster analysis, categories which are low, medium and high were formed for total customer satisfaction scores and the transformation of variable to a categorical variable was done (see Table 6). Analysis revealed acceptable values of cohesion and separation, all $>0.7$ and group ratio, all $<3$ (Rousseeuw, 1987).

Table 4. Two-step cluster analysis results regarding customer loyalty scores.

\begin{tabular}{llllllll}
\hline Cluster & Sub-Group & $\boldsymbol{F}$ & $\mathbf{\%}$ & Min. & Max. & $\overline{\boldsymbol{X}}$ & \multicolumn{1}{c}{$\boldsymbol{s d}$} \\
\hline \multirow{3}{*}{ Customer Loyalty } & Low Score Group & 46 & 13.80 & 3 & 10 & 7.52 & 2.45 \\
& Medium Score Group & 124 & 47.60 & 11 & 14 & 12.89 & 1.11 \\
& High Score Group & 184 & 38.60 & 15 & 21 & 17.05 & 1.96 \\
\cline { 2 - 7 } & Total & 354 & 100 & 3 & 21 & 14.36 & 3.72 \\
\hline
\end{tabular}

Because we obtained the respondents' customer loyalty scores from distinct layers of population, the data set separated in to homogeneous subgroups by using two-step cluster analysis (Chiu, Fang, Chen \& Wang, 2001). By using two-step cluster analysis, categories which are low, medium and high were formed for total customer loyalty scores and the transformation of variable to a categorical variable was done (see Table 7). Analysis revealed acceptable values of cohesion and separation, all $>0.7$ and group ratio, all $<3$ (Rousseeuw, 1987). 


\subsection{Hypotheses testing}

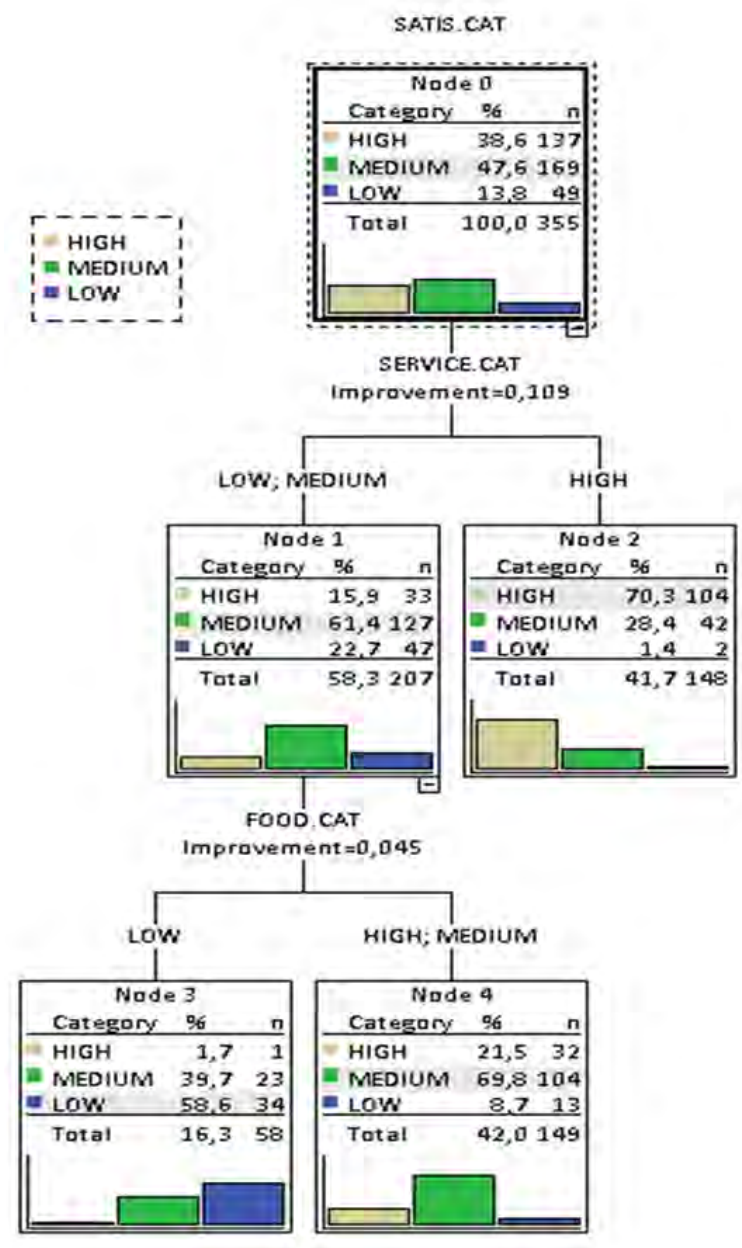

\section{Figure 1. Classification-Tree Diagram Showing the Effect of Independent Variables on Customer Satisfaction Level of Participants.}

In order to investigate how the predictor variables food quality, service quality, mobile application, restaurant atmosphere, price, location and presentation shows levels predict the dependent variable "customer satisfaction" the CART Classification and Regression Tree Method was used. As seen in Figure 1 (The CART procedure used has a risk estimate of 0.28 ), service quality has seen to be the main variable affecting the dependent variable. Three indicated that $70.3 \%$ the customers are highly satisfied who considered the service quality as high and only $1.4 \%$ of the customers have low satisfaction when the service quality considered as high. On the other hand only $15.9 \%$ of the customers are highly satisfied who considered the service quality medium or low. The tree also reveals that food quality may contribute to the satisfaction when the service quality is not highly considered by the customers. Among those who says service quality is low or medium, when food quality is medium or high, only $8,7 \%$ of them have low satisfaction. This means some of the customers consider food quality more than service quality and when it is like this, food quality contribute to satisfaction. None of the other predictors are significantly explaining the dependent variable. 


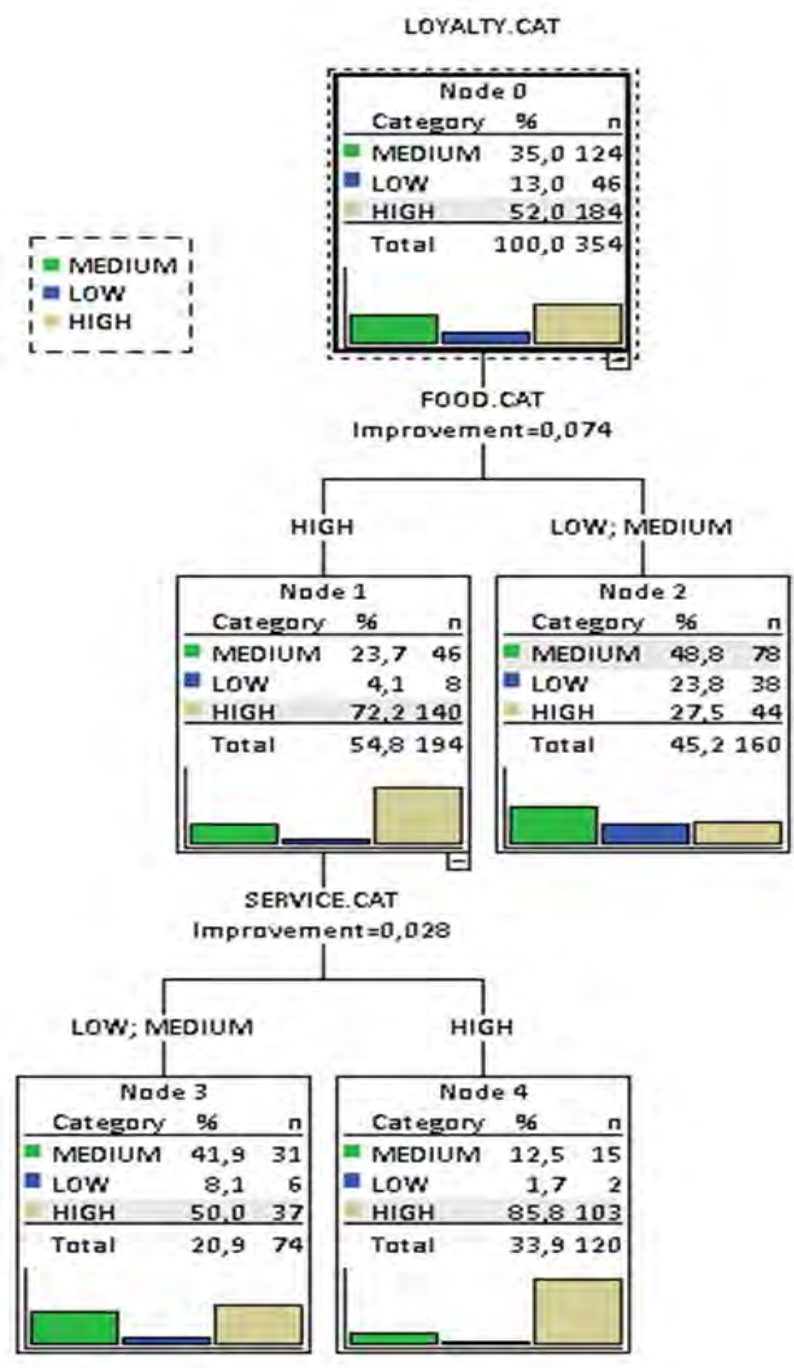

Figure 2. Classification-Tree Diagram Showing the Effect of Independent Variables on Loyalty Level of Participants.

In order to explore how the predictor variables food quality, service quality, mobile application, restaurant atmosphere, price, location and presentation shows levels predict the dependent variable "loyalty" the CART Classification and Regression Tree Method has applied as shown in Figure 2 (The CART procedure used has a risk estimate of 0.3), food quality is the major variable affecting the dependent variable. As seen in the tree, $72.2 \%$ the customers have high loyalty who considered the food quality as high. On the other hand only $27.52 \%$ of the customers have high loyalty who considered the food quality either medium or low. The tree also shows that the customers who are not highly loyal with the food quality do not consider service quality. However, it is seen that service quality contributes to the loyalty of the customers who considers the food quality as high. So this shows us, without a high food quality customer loyalty cannot be achieved. None of the other predictors are significantly explaining the dependent variable. 


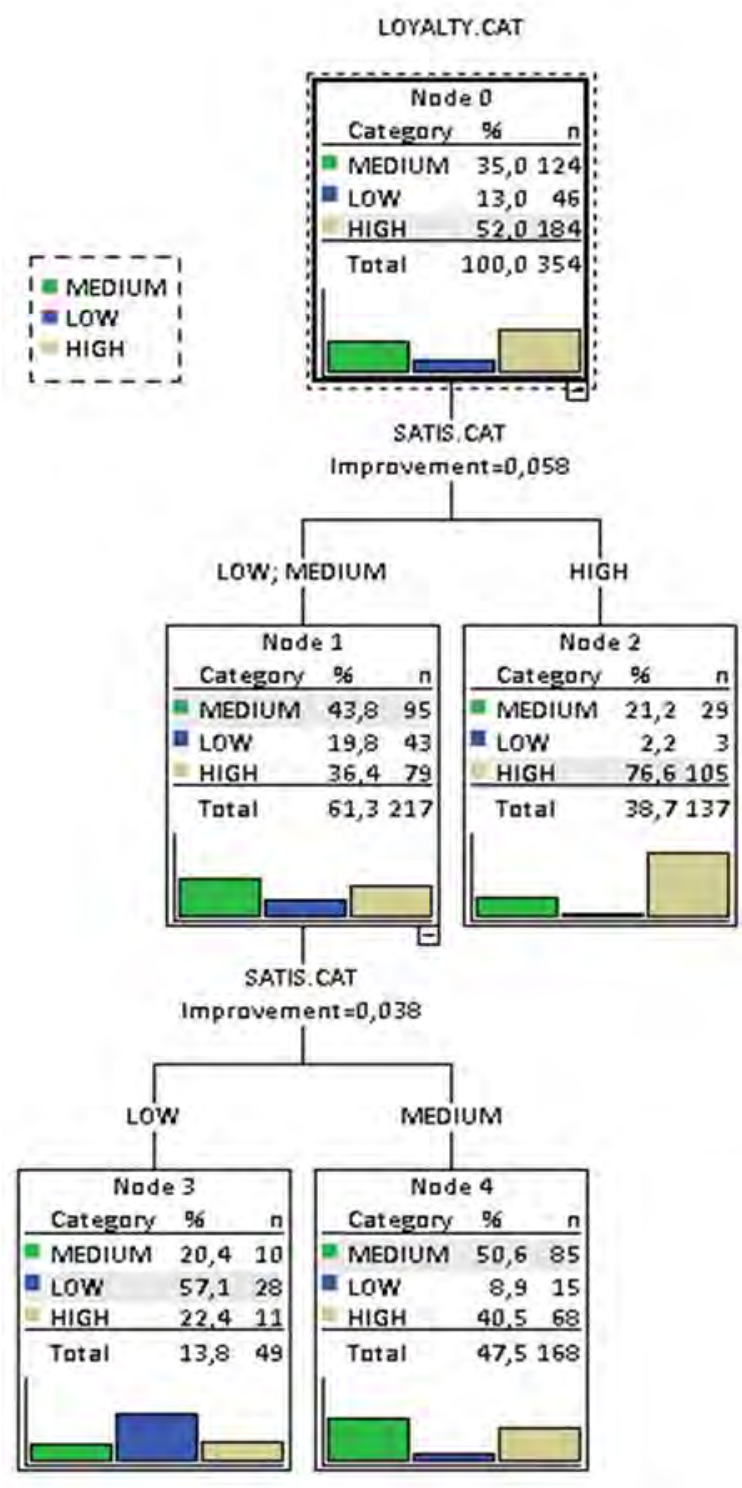

Figure 3. Classification-Tree Diagram Showing the Effect of Customer Satisfaction on Loyalty Level of Participants.

In order to examine how the predictor variable customer satisfaction levels predict the dependent variable "loyalty" the CART Classification and Regression Tree Method was used as seen in Figure 3 (The CART procedure used has a risk estimate of 0.25 ). As seen in the tree, $76.6 \%$ the customers have high loyalty who has high satisfaction. Only $36.4 \%$ of the customers have high loyalty who has low or medium satisfaction. Then the tree examine the customers who have low or medium satisfaction. When we look at who has low satisfaction, $22.4 \%$ of them have loyalty but when the satisfaction level rise to medium level the customers have $40.5 \%$ loyalty which is nearly two times bigger. This means a slight increase in satisfaction can create dramatic rise on loyalty and this shows us the vital importance of the customer satisfaction. None of the other predictors are significantly explaining the dependent variable.

\section{DISCUSSION}

\subsection{Evaluation of findings and theoretical implications}

Our findings indicate that the values and expectations of customers in TRNC is different when compared with previous studies in the literature. Each country can have its own culture and values and these may create differences in values and expectations. The literature suggest that differences may occur even in different 
regions of the same country (Zhang \& Law, 2013). Therefore, purpose of our study was to test service quality, food quality, price, location and restaurant atmosphere in TRNC which are widely mentioned in literature and found to be effective drivers of customer satisfaction in restaurant industry. However positive relationships have found only between service quality and food quality in relation to customer satisfaction. In addition, two new factors, mobile applications and presentation show have incorporated to test the relationship with customer satisfaction. Results indicate that service quality is the most effective driver of customer satisfaction among the other factors, followed by food quality. Furthermore, result of our study confirms the positive relationship between customer satisfaction and customer loyalty, similar to previous studies in literature (Heskett et al., 1994; Shahin \& Javadi, 2011; Hoyer \& Pieters, 2001).

\subsection{Practical Implication}

The findings of our study shows that only service quality and food quality leads to increase in customer satisfaction in restaurant industry of TRNC where service quality was the first and food quality was the second significant determinant of customer satisfaction. Thus managers in TRNC should focus on these two dimensions to create customer satisfaction and retention in return. Restaurant managers in TRNC should pay attention on food freshness and food temperature which are the determinants of food quality. Lastly, the results showed us that females in TRNC are more loyal than males in restaurant industry. This can give us a clue that women plays important role in selecting the restaurant. Therefore, managers should make the restaurant's design and arrangements in a way that attracts women.

\subsection{Limitations of the study and future research directions}

Our study applied convenience sampling and future studies may use the same proposed research model through different sampling methods. In addition, the areas for future research may include the moderating role of trust and commitment in the components and customer satisfaction as well as satisfaction-loyalty relationship might examined. Our results suggest that females display more loyalty in restaurant industry, thus future studies may also investigate the factors that make women more loyal then males.

\section{REFERENCES}

Andaleeb, S. S., \& Conway, C. (2006). Customer satisfaction in the restaurant industry: an examination of the transaction-specific model. Journal of services marketing.

Anderson, E. W., C. Fornell and R. T. Rust (1997). "Customer satisfaction, productivity, and profitability: Differences between goods and services." Marketing science 16(2): 129-145.

Anderson, E. W., \& Sullivan, M. W. (1993). The antecedents and consequences of customer satisfaction for firms. Marketing science, 12(2), 125-143.

Azim, A., Shah, N. A., Mehmood, Z., Mehmood, S., \& Bagram, M. M. M. (2014). Factors effecting the customer's selection of restaurants in Pakistan. International Review of Management and Business Research, 3(2), 1003.

Bansal, S., \& Gupta, G. (2001). Building customer loyalty business-to-business commerce. Customer Relationship Management: Emerging Concepts, Tools, and Applications, 1, 273-291.

Balasubramanian, K., Balraj, A., \& Kumar, J. (2015). Customer preference's to select a restaurant through smart phone applications: an exploratory study. Advanced Science Letters, 21(5), 1489-1493.

Bearden, W. O., \& Teel, J. E. (1983). Selected determinants of consumer satisfaction and complaint reports. Journal of marketing Research, 20(1), 21-28.

Butt, H. S. and M. Murtaza (2011). "Measuring customer satisfaction wrt restaurant industry in Bahawalpur." European Journal of Business and Management 3(5): 54-64.

Bowen, J. T., \& Chen, S. L. (2001). The relationship between customer loyalty and customer satisfaction. International journal of contemporary hospitality management.

Cardello, A. V. (1995). Food quality: relativity, context and consumer expectations. Food quality and preference, 6(3), 163-170. 
Chandrashekaran, R., \& Grewal, D. (2003). Assimilation of advertised reference prices: the moderating role of involvement. Journal of Retailing, 79(1), 53-62.

Chang, K. (2000). The impact of perceived physical environments on customers' satisfaction and return intentions. Journal of Professional Services Marketing, 21(2), 75-85.

Chebat, J. C., \& Michon, R. (2003). Impact of ambient odors on mall shoppers' emotions, cognition, and spending: A test of competitive causal theories. Journal of business research, 56(7), 529-539.

Chiu, T. - Fang, D. Chen, J. - Wang, Y. - Jeris, C. 2001: A Robust and Scalable Clustering Algorithm for Mixed Type Attributes in Large Database Environment. Proceedings of the seventh ACM SIGKDD international conference on knowledge discovery and data mining, SanFrancisco, CA: ACM, 263-268.

Dancey C.P., Reidy J. (2007). Statistics without Maths for Psychology. Pearson Education

Eshghi, A, Haughton,D., and Topi H., (2007),"Determinants of customer loyalty in the wireless telecommunication industry", Telecommunication policy, Volume 31, Issue 2, Pages 93-96

Gagić, S., D. Tešanović and A. Jovičić (2013). "The vital components of restaurant quality that affect guest satisfaction." Turizam 17(4): 166-176.

Galvez, F. C. F., \& Resurreccion, A. V. (1992). Reliability of the focus group technique in determining the quality characteristics of mungbean [Vigna radiata (L.) wilczec] noodles. Journal of Sensory Studies, $7(4), 315-326$

Gounaris, S. (2005). Measuring service quality in b2b services: an evaluation of the SERVQUAL scale vis-à-vis the INDSERV scale. Journal of Services Marketing.

Gray, B., \& Boshoff, C. (2004). The relationships between service quality, customer satisfaction and buying intentions in the private hospital industry. South African journal of business management, 35(4), 2737.

Fornell, C., Johnson, M. D., Anderson, E. W., Cha, J., \& Bryant, B. E. (1996). The American customer satisfaction index: nature, purpose, and findings. Journal of marketing, 60(4), 7-18.

Fu, Y. Y., \& Parks, S. C. (2001). The relationship between restaurant service quality and consumer loyalty among the elderly. Journal of Hospitality \& Tourism Research, 25(3), 320-326.

Furrer, O., Liu, B. S. C., \& Sudharshan, D. (2000). The relationships between culture and service quality perceptions: Basis for cross-cultural market segmentation and resource allocation. Journal of service research, 2(4), 355-371.

Hackl, P., \& Westlund, A. H. (2000). On structural equation modelling for customer satisfaction measurement. Total Quality Management, 11(4-6), 820-825.

Haghighi, M., A. Dorosti, A. Rahnama and A. Hoseinpour (2012). "Evaluation of factors affecting customer loyalty in the restaurant industry." African Journal of Business Management 6(14): 5039-5046.

Han, H., \& Ryu, K. (2009). The roles of the physical environment, price perception, and customer satisfaction in determining customer loyalty in the restaurant industry. Journal of hospitality \& tourism research, 33(4), 487-510.

Hanaysha, J. (2016). Restaurant location and price fairness as key determinants of brand equity: A study on fast food restaurant industry. Business and Economic Research, 6(1), 310-323.

Heller, L (2011), Hilton gets100, 000 hotel bookings from mobile apps. Retrieved from http://www.bighospitality.co.uk/Business/Hilton-gets-100-000-hotelbookings-from-mobile-apps

Hennig-Thurau, T., \& Klee, A. (1997). The impact of customer satisfaction and relationship quality on customer retention: A critical reassessment and model development. Psychology \& marketing, 14(8), 737-764.

Heskett, J. L., Jones, T. O., Loveman, G. W., Sasser, W. E., \& Schlesinger, L. A. (1994). Putting the service-profit chain to work. Harvard business review, 72(2), 164-174.

Hokanson, S. (1995). The deeper you analyze, the more you satisfy customers. Marketing News, 29(1), 16-16.

Hoyer, W. D., D. J. Macinnis and R. Pieters (2001). "Customer behavior." Boston, Houghton Mifflin Company.

Hul, M. K., Dube, L., \& Chebat, J. C. (1997). The impact of music on consumers' reactions to waiting for services. Journal of retailing, 73(1), 87-104. 


\section{E. Ruhluel - P. Bayram 13/3 (2021) 2305-2319}

Hwang, J., \& Zhao, J. (2010). Factors influencing customer satisfaction or dissatisfaction in the restaurant business using AnswerTree methodology. Journal of Quality Assurance in Hospitality \& Tourism, 11(2), 93-110.

Khan, I. (2012). Impact of customers satisfaction and customers retention on customer loyalty. International Journal of Scientific \& Technology Research, 1(2), 106-110.

Kotler, P. \& Armstrong, G. (2010), "Principles of Marketing", 13th Ed. New Jersey: Prentice Hall.

Kotler, P. , (2000) ,Marketing Managment. 10th ed., New Jersey, Prentice-Hall

LaBarbera, P. A., \& Mazursky, D. (1983). A longitudinal assessment of consumer satisfaction/dissatisfaction: the dynamic aspect of the cognitive process. Journal of marketing research, 20(4), 393-404.

Lee, M., \& Ulgado, F. M. (1997). Consumer evaluations of fast-food services: a cross-national comparison. Journal of Services Marketing.

Li, W., Ding, Y., Deng, D., Jiang, W., \& Liu, Z. (2015). Empirical Analysis of the Relationship Between Brand Marketing Strategies and Marketing Performance of Agricultural Science and Technology Enterprises. In Proceedings of the Ninth International Conference on Management Science and Engineering Management (pp. 1097-1107). Springer, Berlin, Hedelber.

Liao, H., \& Chuang, A. (2004). A multilevel investigation of factors influencing employee service performance and customer outcomes. Academy of Management journal, 47(1), 41-58.

Liu, Y., \& Jang, S. S. (2009). Perceptions of Chinese restaurants in the US: what affects customer satisfaction and behavioral intentions?. International Journal of Hospitality Management, 28(3), 338-348.

MacLaurin, D. J., \& MacLaurin, T. L. (2000). Customer perceptions of Singapore's theme restaurants. Cornell Hotel and Restaurant Administration Quarterly, 41(3), 75-85.

Mankaa, C. T. (2012). The Relationship between Voluntary Turnover and Customer Satisfaction in the Restaurant Business: A Case in Five Restaurants in Famagusta, North Cyprus (Doctoral dissertation, Eastern Mediterranean University (EMU)).

Markovic, S., Raspor Jankovic, S., \& Dorcic, J. (2011). What are the key dimensions of restaurant service quality? An empirical study in the city restaurant settings. An Empirical Study in the City Restaurant Settings (May 03, 2011). Sustainable Tourism: Socio-Cultural, Environmental and Economic Impact, 235-249.

Mehrabian, A., \& Russell, J. A. (1974). An approach to environmental psychology. the MIT Press.

Melia, D. (2010). Critical success factors and performance management and measurement: A hospitality context.

Milliman, R. E. (1986). The influence of background music on the behavior of restaurant patrons. Journal of consumer research, 13(2), 286-289.

Parasuraman, A., \& Zeithaml, V. (85). a., \& Berry, LL (1988). SERVQUAL: A multiple-Item Scale for Measuring Consumer Perceptions of Service Quality, 12-40.

Parsa, H. G., Self, J. T., Njite, D., \& King, T. (2005). Why restaurants fail. Cornell Hotel and Restaurant Administration Quarterly, 46(3), 304-322.

Rousseeuw, P, J. (1987). "Silhouettes: a Graphical Aid to the Interpretation and Validation of Cluster Analysis". Computational and Applied Mathematics.

Ryu, K., \& Han, H. (2010). Influence of the quality of food, service, and physical environment on customer satisfaction and behavioral intention in quick-casual restaurants: Moderating role of perceived price. Journal of Hospitality \& Tourism Research, 34(3), 310-329.

O'dea J. (2020).Number of smartphone users worldwide from 2016 to 2020 (in billions). Retrieved from: https://www.statista.com/statistics/330695/number-of-smartphone-users-worldwide/(Accessed 10 June 2019).

Qin, H., \& Prybutok, V. R. (2009). Service quality, customer satisfaction, and behavioral intentions in fast-food restaurants. International Journal of Quality and Service Sciences.

Oliver, R. L. (1980). A cognitive model of the antecedents and consequences of satisfaction decisions. Journal of marketing research, 17(4), 460-469. 
E. Ruhluel - P. Bayram 13/3 (2021) 2305-2319

Oliver, R.L. (1997). " Satisfaction: A Behavioural Perspective on the Consumer",New York,Mc Graw Hill.

Singh, H. (2006). "The importance of customer satisfaction in relation to customer loyalty and retention." Academy of Marketing Science 60(193-225): 46.

Sabir, R. I., O. Ghafoor, I. Hafeez, N. Akhtar and A. U. Rehman (2014). "Factors affecting Customers satisfaction in Restaurants industry in Pakistan." International Review of Management and Business Research 3(2): 869.

Shahin, A., Abandi, A. A., \& Javadi, M. H. M. (2011). Analyzing the relationship between customer satisfaction and loyalty in the software industry-with a case study in Isfahan System Group. International Journal of Business and Social Science, 2(23).

Stevens, P., Knutson, B., \& Patton, M. (1995). DINESERV: A tool for measuring service quality in restaurants. The Cornell Hotel and Restaurant Administration Quarterly, 36(2), 5-60.

T.R.N.C Ministry of National Education and Culture (2019). Yüksek öğrenime dair aradığınız her şey. Retrieved from: https://yobis.mebnet.net/default.aspx. (Accessed on 15.01.2020).

Wang, L. W., Tran, T. T., \& Nguyen, N. T. (2014). Analyzing factors to improve service quality of local specialties restaurants: A comparison with fast food restaurants in southern Vietnam. Asian Economic and Financial Review, 4(11), 1592.

Wakefield, K. L., \& Blodgett, J. G. (1994). The importance of servicescapes in leisure service settings. Journal of services marketing.

Xia, L., Monroe, K. B., \& Cox, J. L. (2004). The price is unfair! A conceptual framework of price fairness perceptions. Journal of marketing, 68(4), 1-15.

Yang, Z., \& Peterson, R. T. (2004). Customer perceived value, satisfaction, and loyalty: The role of switching costs. Psychology \& marketing, 21(10), 799-822.

Zhang, Z., Zhang, Z., \& Law, R. (2013). Regional effects on customer satisfaction with restaurants. International Journal of Contemporary Hospitality Management.

Zopiatis, A., \& Pribic, J. (2007). College students' dining expectations in Cyprus. British Food Journal,Vol. 109, No. 10, pp. $765-776$ 